\title{
Spatial and temporal patterns in development of eggs in the vent crab Bythograea thermydron
}

\author{
Gina M. Perovich ${ }^{1, *}$, Charles E. Epifanioº ${ }^{2}$ Ana I. Dittel ${ }^{2}$, Paul A. Tyler ${ }^{3}$ \\ ${ }^{1}$ United States Environmental Protection Agency (8723R), 1200 Pennsylvania Avenue, NW, Washington, DC 20460, USA \\ ${ }^{2}$ University of Delaware, Graduate College of Marine Studies, 700 Pilottown Road, Lewes, Delaware 19958, USA \\ ${ }^{3}$ School of Ocean and Earth Science, University of Southampton, Southampton Oceanography Centre, \\ Southampton SO14 3ZH, United Kingdom
}

\begin{abstract}
In this paper we describe results of a study on the reproductive biology of the hydrothermal vent crab Bythograea thermydron. At vent sites along the East Pacific Rise, histological analyses of gonads from adult female crabs collected in November 1997, May 1999 and May 2000 provide strong evidence that $B$. thermydron undergoes a seasonal cycle of reproductive activity, with egg hatching peaking in April-May. Females undergo a synchronous pattern of oocyte development, whereby one cohort of oocytes undergoes vitellogenesis, while a second cohort is present and remains immature until the initial cohort reaches full maturity and is extruded onto the pleopods. When mean oocyte-size-frequency distributions were compared across months, the 2 May samples were similar to each other, with a dominance of previtellogenic oocytes and a second, smaller group of vitellogenic oocytes also present. In contrast, the November sample exhibited a wide variety of oocyte sizes, with no one size class predominating. In addition, May samples from the vent periphery contained a high proportion of females that showed evidence of recent egg hatching, while females collected from the region near the vent orifice exhibited a wide range of the intermediate stages of gonadal development. This set of data suggests an annual cycle whereby a given cohort of oocytes is in a previtellogenic state in early spring (April-May), but has begun vitellogenesis by late autumn (November) and has developed to maximum maturity by the time the eggs are extruded the following spring. While the current clutch of eggs is being brooded, a second cohort of previtellogenic oocytes begins to develop in the ovary and the cycle is repeated. Superimposed on this annual cycle is a pattern of behavior whereby females with mature gonads migrate to the vent periphery where fertilized eggs are extruded, brooded, and hatched.
\end{abstract}

KEY WORDS: Hydrothermal vents - Egg development - Seasonality - Vent crab · Bythograea Resale or republication not permitted without written consent of the publisher

\section{INTRODUCTION}

The majority of studies on seasonality and reproduction in the deep sea have been conducted in the last 2 decades (e.g. Tyler 1988, Gage \& Tyler 1991, Company \& Sarda 1997). However, it was in 1920 that Orton first introduced the hypothesis that, because the physical environment in the deep sea does not experience seasonal temperature variation, the breeding period of deep-sea species would be expected to be continuous throughout the year. The study of deep-sea reproductive biology has arisen from testing this hypothesis.
Early evidence that contradicted Orton's hypothesis was reported by Schoener (1968), who documented seasonality in the population structure of 2 brittlestars from a deep-sea environment in the NW Atlantic. Studies by George \& Menzies (1967, 1968) also revealed cyclic reproductive activity in isopods from the Scotia Sea near Antarctica. In addition, Rokop $(1974,1977)$ reported reproductive seasonality in 1 species of brachiopod and 1 species of scaphopod from the San Diego Trough off southern California. More recent evidence of seasonality has come from the Rockall Trough off the west coast of Ireland, where 20 
out of 79 taxonomically diverse species showed evidence of seasonality in their reproductive patterns (reviewed in Harrison 1988).

In shallow-water habitats, seasonality in reproduction has long been correlated with periodic variations in the physical environment, e.g. temperature, day length, rainfall, tidal and lunar phases (e.g. Giese 1959). In the absence of such variation in the deep sea, it is more difficult to explain seasonality in those species in which it occurs (Tyler 1986, 1988, Gage \& Tyler 1991). However, recent work has pointed to seasonal variation in the flux of phytodetritus from surface waters to the deep sea as a potential zeitgeber of reproductive cycles in this environment (Tyler et al. 1983, Campos-Creasey et al. 1994, Smith et al. 1996). While this is an attractive hypothesis for many deep-sea habitats, it is less compelling for hydrothermal vent systems where the food web is dominated by endogenous chemosynthetic production that shows no annual periodicity in its occurrence. Thus, it might be expected that seasonal patterns of reproduction would be rare among the animals indigenous to vent habitats.

Hydrothermal vents occur along the global midocean ridge system and are associated with areas of sea-floor spreading. The majority of biomass is found close to the vent orifice (Hessler et al. 1985, Hessler \& Kaharl 1995). This area is characterized by elevated temperatures and high levels of $\mathrm{H}_{2} \mathrm{~S}$. The fauna is dominated by organisms that harbor endosymbiotic bacteria, such as vestimentiferan tubeworms, vesicomyid clams, and mussels (Grassle 1986). A few meters removed from the orifice is the near-field region, which is inhabited by sessile suspensionfeeders such as serpulid polychaetes (Hessler \& Kaharl 1995). This area is characterized by steep gradients in temperature and $\mathrm{H}_{2} \mathrm{~S}$. Even farther removed from the orifice is the vent-periphery region. Chiefly populated by non-vent animals, such as enteropneusts and holothurians, this area is the least studied and the least understood (Hessler \& Kaharl 1995). Water temperatures and levels of $\mathrm{H}_{2} \mathrm{~S}$ in this region approach ambient deep-sea conditions.

One of the more common crustaceans at vent sites along the East Pacific Rise is the hydrothermal vent crab Bythograea thermydron (Van Dover et al. 1987). Williams first described the crab in 1980, placing $B$. thermydron in a new family (Bythograeidae) that shares morphological characteristics with the Xanthidae, Portunidae, and Potamidae. B. thermydron is an obligate vent species and has a remarkable tolerance for variation in temperature and $\mathrm{H}_{2} \mathrm{~S}$ levels (Mickel \& Childress 1982a,b, Vetter et al. 1987). Adults and juveniles have been most commonly observed near the vent orifice, where they appear to feed on vestimen- tiferan tubeworms, mussels, and other sessile invertebrates (Van Dover 2000).

While some aspects of the physiology of this crab have been studied extensively (reviewed in Childress \& Fisher 1992), little is known of the reproductive biology of the species. Brachyuran crabs generally have internal fertilization following copulation that often occurs immediately after the female has molted. The male deposits sperm packets in the female, providing her with the potential to fertilize more than 1 batch of eggs. Fertilized eggs are then deposited onto the pleopods and brooded until hatching. While Bythograea thermydron presumably demonstrates a similar pattern of copulation and fertilization, ovigerous females are rarely observed at the vent orifice. Thus, it has been assumed that they occupy a distinctly different habitat during the brooding period. It is not known how long females brood the eggs before hatching (Van Dover 2000). After hatching, the larvae appear to undergo planktotrophic development that includes an unknown number of zoeal stages and a megalopal stage (Williams 1980). Megalopae are unique in their large size and in their ability to withstand large variations in temperature and hydrostatic pressure (Epifanio et al. 1999).

In this paper, we describe results from a study of the reproductive biology of Bythograea thermydron at several vent sites along the East Pacific Rise. We investigated the seasonality of gonadal development in sexually mature female crabs and the spatial distribution of mature female crabs in various stages of gonadal development, ranging from females with undifferentiated ovaries to females that were actively brooding eggs.

\section{MATERIALS AND METHODS}

Field sampling. Crabs were collected on 3 different cruises aboard the RV 'Atlantis', using the deep-sea submersible 'Alvin'. The dives took place during November 1997, May 1999 and May 2000 at the $9^{\circ} \mathrm{N}$ vent field on the East Pacific Rise off the coast of Central America $\left(9^{\circ} 50^{\prime} \mathrm{N}, 104^{\circ} 17^{\prime} \mathrm{W}\right.$; Fig. 1). This vent field is comprised of a number of discrete vent sites at an average depth of about $2500 \mathrm{~m}$. During each cruise, the majority of samples were obtained from 3 primary vent sites within the $9^{\circ} \mathrm{N}$ vent field (Fig. 1, inset). The first of these was Q Vent, which is situated on the sloping eastern wall of the Axial Summit Caldera. The second site was Bio Vent, which is a relatively flat site with zones of fauna radiating out from a central chimney. The last site was Tica, which is similar to Q Vent in appearance (Fig. 1).

Crabs were collected by directed sampling or as specimens-of-opportunity associated with other pro- 


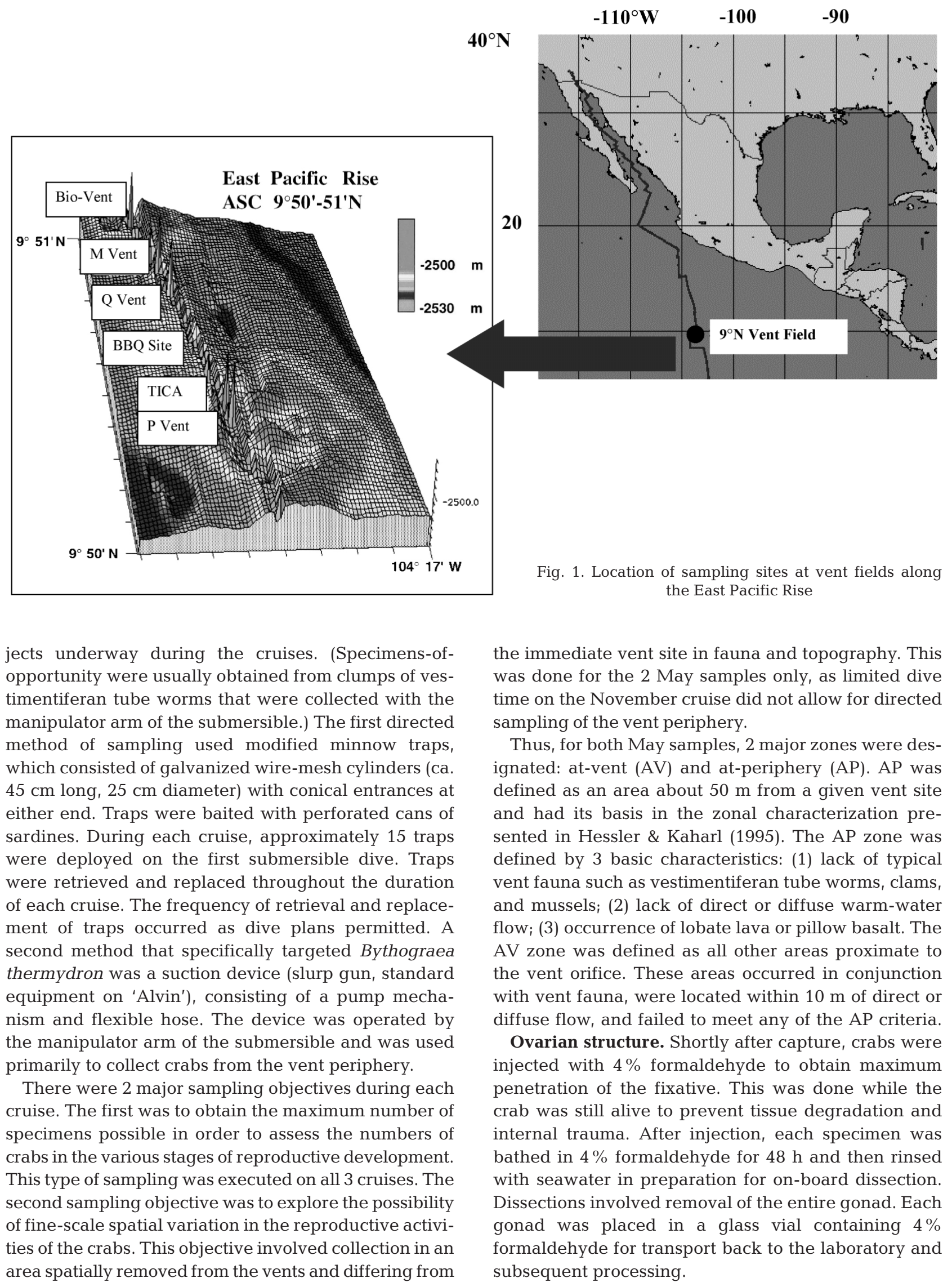


Once in the laboratory, the preserved gonads were dehydrated through a series of graded alcohol solutions and cleared in xylene. The tissue was embedded in paraffin wax, and $5 \mu \mathrm{m}$ sections were taken at 3 different levels within the block of tissue. Sections were stained with hematoxylin and eosin, and microscopic examination was performed using the SigmaScan Pro 4 image analysis system. For each individual, a total of 150 oocytes (50 per slide) that had been sectioned through the nucleus were selected, and the area within each cell was determined by the image analysis system. This value was used to calculate the feret diameter of the cell. Feret diameter is the diameter of a hypothetical circle having the same area as the object being measured. In all subsequent analyses, feret diameter was used as an index of oocyte size.

Synchronicity of oocyte development. To determine the existence of synchronous gonadal development within each specimen, oocyte size-frequency distributions were plotted for all specimens obtained. Oocytes within a given ovary were grouped into size classes in increments of $25 \mu \mathrm{m}$, ranging from 0 to $575 \mu \mathrm{m}$ ( $\mathrm{n}=$ 150 oocytes per crab for 110 crabs). The percentage of oocytes in each category was then calculated for each individual crab and the resulting distributions graphed and examined for synchrony. A wide distribution of oocyte sizes in a single specimen indicates that the oocytes are maturing at different times. In such a case, gametogenesis is said to be asynchronous. Modes in the frequency distribution that are narrow and center around a certain oocyte size imply that the oocytes are maturing simultaneously. This is indicative of synchronous gametogenesis.

Seasonal periodicity. To determine the existence of seasonal periodicity in reproductive activity, a mean oocyte size-frequency distribution was calculated for all female crabs captured within a given month. (In this analysis we used only those crabs captured in the AV zone because specimens were not collected from the AP zone during the November cruise.) Respective mean values for each oocyte size class for crabs collected in November 1997, May 1999 and May 2000 were compared across months using a non-parameteric Kruskal-Wallis test. Non-parametric analysis was used because initial inspection of the data indicated that variates were not normally distributed (KolmogorovSmirnov test of normality). Significance was determined at $\alpha=0.05$. Mean frequencies were then plotted for each size-class. This technique allowed visualization of the oocyte size-frequency distribution for the population of crabs sampled each month.

Spatial variation in reproductive maturity. To investigate geographical variation in maturity, only the May 1999 and May 2000 samples were used (as mentioned, no crabs were available from the periphery in Novem- ber). The mean individual oocyte size was calculated for each crab within a geographical site, either AV or AP. These data deviated from the normal distribution (Kolmogorov-Smirnov test of normality). The 2-sample Kolmogorov-Smirnov test was used to compare mean oocyte sizes at the 2 sites. Significance was determined at $\alpha=0.05$. Separate analyses were conducted for the 2 sampling periods. In a related graphical approach, mean oocyte size-frequency distributions were determined for the respective sites for each May sample.

Spatial variation in sex ratio. In this analysis we initially compared the ratio of mature male to mature female crabs collected during each sampling month. Formal comparison was made with a chi-square test assuming an expected frequency of 0.5 males and 0.5 females. Significant deviation from the expected frequency was determined at $\alpha=0.05$. In a subsequent analysis, we compared the proportions of mature males and mature females respectively in the AV zone and in the AP zone. Formal comparison was again made with a chi-square test assuming an expected frequency of 0.5 males and 0.5 females. Separate analysis was done for each of the zones. This analysis was done only for the May 1999 and May 2000 data, as crabs were not collected at the AP site in November 1997.

\section{RESULTS}

Ovarian structure. Histological analysis indicated that ovarian microstructure in Bythograea thermydron is similar to that in shallow-water brachyuran crabs (Johnson 1980). The germinative centers are composed of oogonia that run in strands longitudinally throughout the ovary (Fig. 2). The youngest oocytes arising from the oogonia measure about $15 \mu \mathrm{m}$ feret diameter. Previtellogenic oocytes contain little cytoplasm. Nuclei are large in relation to cell volume, and more than 1 nucleolus was frequently observed (usually 2 to 3 ). Vitellogenesis begins when cells reach about $150 \mu \mathrm{m}$ in diameter. The developing oocytes, which change from round to ovoid shape as development progresses, are surrounded by accessory cells. At completion of vitellogenesis, there are still oogonia and previtellogenic oocytes along the germinative strands.

Synchronicity of ovarian development. Overall, we examined the oocyte size-frequency distributions in the ovaries of 110 crabs. These distributions show evidence of synchronous oogenesis, as evidenced by the 3 common patterns of oocyte distributions into which each of the 110 specimens fall (Fig. 3). The first pattern (previtellogenic) was characterized by a leftskewed, unimodal distribution of oogonia and previtellogenic oocytes $(<150 \mu \mathrm{m})$. A second pattern (vitellogenic) was characterized by a bimodal distribution 


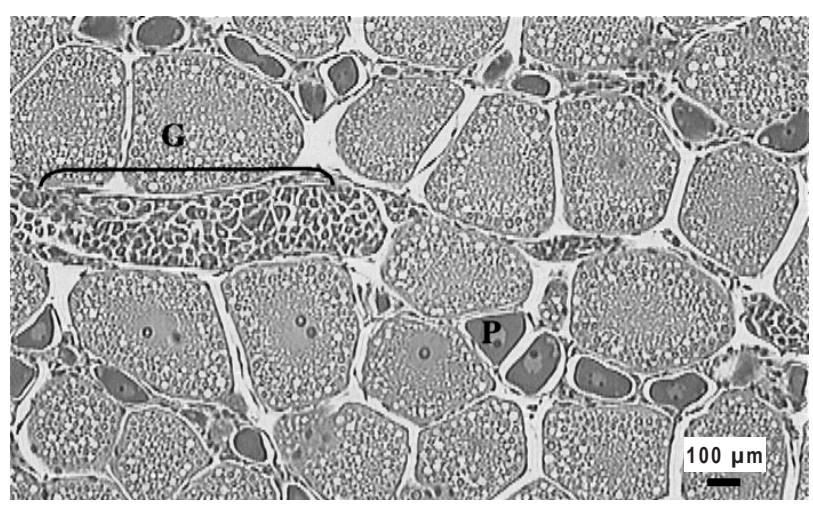

Fig. 2. Bythograea thermydron. Ovary in late developmental stage $(40 \times)$. Ovary is mostly comprised of mature vitellogenic oocytes (V), but germinative strands (G) and a few previtellogenic oocytes $(\mathrm{P})$ are present

showing a core group of previtellogenic oocytes $(<150 \mu \mathrm{m})$ and a second cohort of oocytes that had begun to undergo vitellogenesis (150 to $250 \mu \mathrm{m}$ ). The 2 modes appeared similar in magnitude. A final pattern (mature) was also bimodal, although the modes were unequal. This last pattern was characterized by a large cohort of mature oocytes $(\sim 500 \mu \mathrm{m})$ and a distinctly smaller cohort of previtellogenic oocytes $(<150 \mu \mathrm{m})$. These patterns suggest that Bythograea thermydron undergoes synchronous gametogenesis and iteroparous reproduction, whereby 1 cohort of oocytes undergoes vitellogenesis while a second cohort is present, the latter developing only after mature oocytes are extruded onto the pleopods.

Seasonal periodicity. Results of a Kruskal-Wallis test indicated a significant effect of time-of-year on the mean oocyte size of crabs collected in the AV zone in November 1997, May 1999, and May $2000(H=11.773, \mathrm{df}=2$, $\mathrm{p}=0.003$ ). Fig. 4 shows the mean oocyte size frequencies for each month plotted with standard errors. The 2 May samples are similar to each other and are dominated by previtellogenic oocytes, while the November sample shows a wide variety of oocyte sizes.

Spatial variation in reproductive maturity. Nonparametric analysis (2-sample Kolmogorov-Smirnov test) showed a significant difference between the 2 zones AV and AP for the May 2000 sample (Z-statistic $=1.693, \mathrm{p}=0.006)$, while the May 1999 sample showed no significant statistical difference $(Z$-statistic $=1.023$, $p=0.246$ ). Because the numbers driving these differences in distribution are the result of greater maximum oocyte sizes in May 2000 than May 1999, these data are better visualized as percent frequency. Fig. 5 presents the cumulative oocyte size-frequency distributions for each zone grouped by month and plotted with standard errors. Despite the fact that no statistically significant difference was found in the May 1999 sample, trends for the 2 sampling periods are similar, i.e. the majority of intermediate oocytes were contributed by samples from the AV zone, while the majority of previtellogenic and mature oocytes were contributed by samples from the AP zone. In addition, about $57 \%$ of the females in the May 1999 AP sample and $72 \%$ of the females in the May 1999 AP sample were either gravid or showed evidence of having just released their brood (Table 1). This evidence consisted of unhatched eggs, empty egg capsules, and attachment stalks still present on the abdominal pleopods of a female. This condition is termed 'remnants' in Table 1. In contrast, both AV samples we dominated by intermediate stages of maturity, and any remnants observed were light, with the exception of only 1 individual with heavy remnants present in the May 2000 AV sample. These data suggest that Bythograea thermydron females release their larvae in the peripheral region of the vent field, returning to the immediate vent area after egg hatching is completed.

Spatial variation in sex ratio. For the total number of crabs collected in each cruise, the results of chi-square analysis revealed no significant difference from the
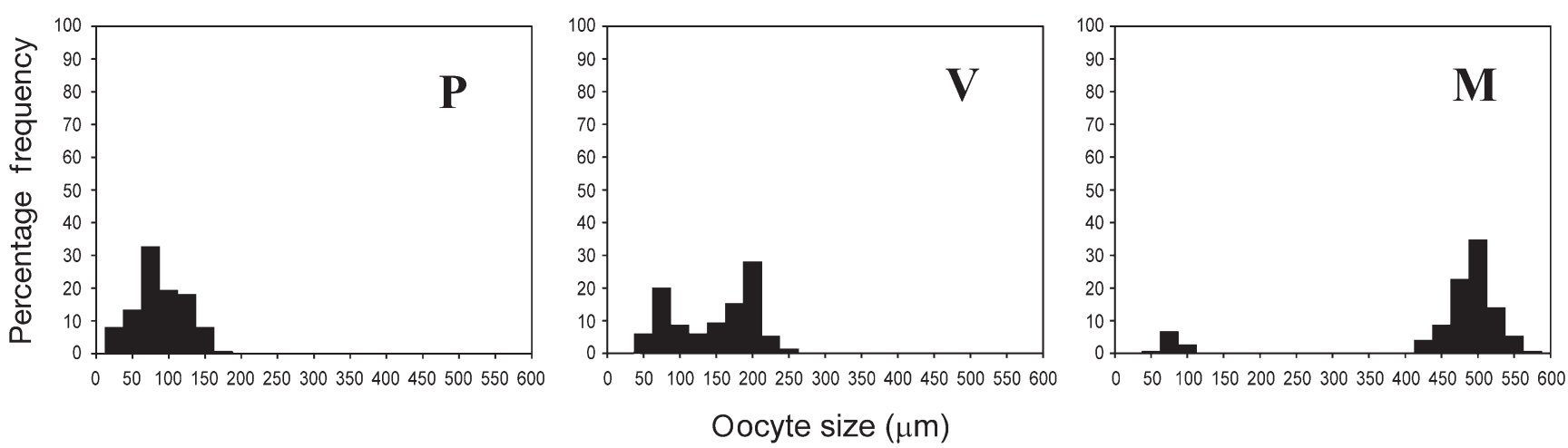

Fig. 3. Bythograea thermydron. Examples of size distribution of oocytes in ovaries. P: crab in previtellogenic stage (May 2000). $\mathrm{V}$ : crab in vitellogenic stage (November 1997); M: crab in mature stage (November 1997) 

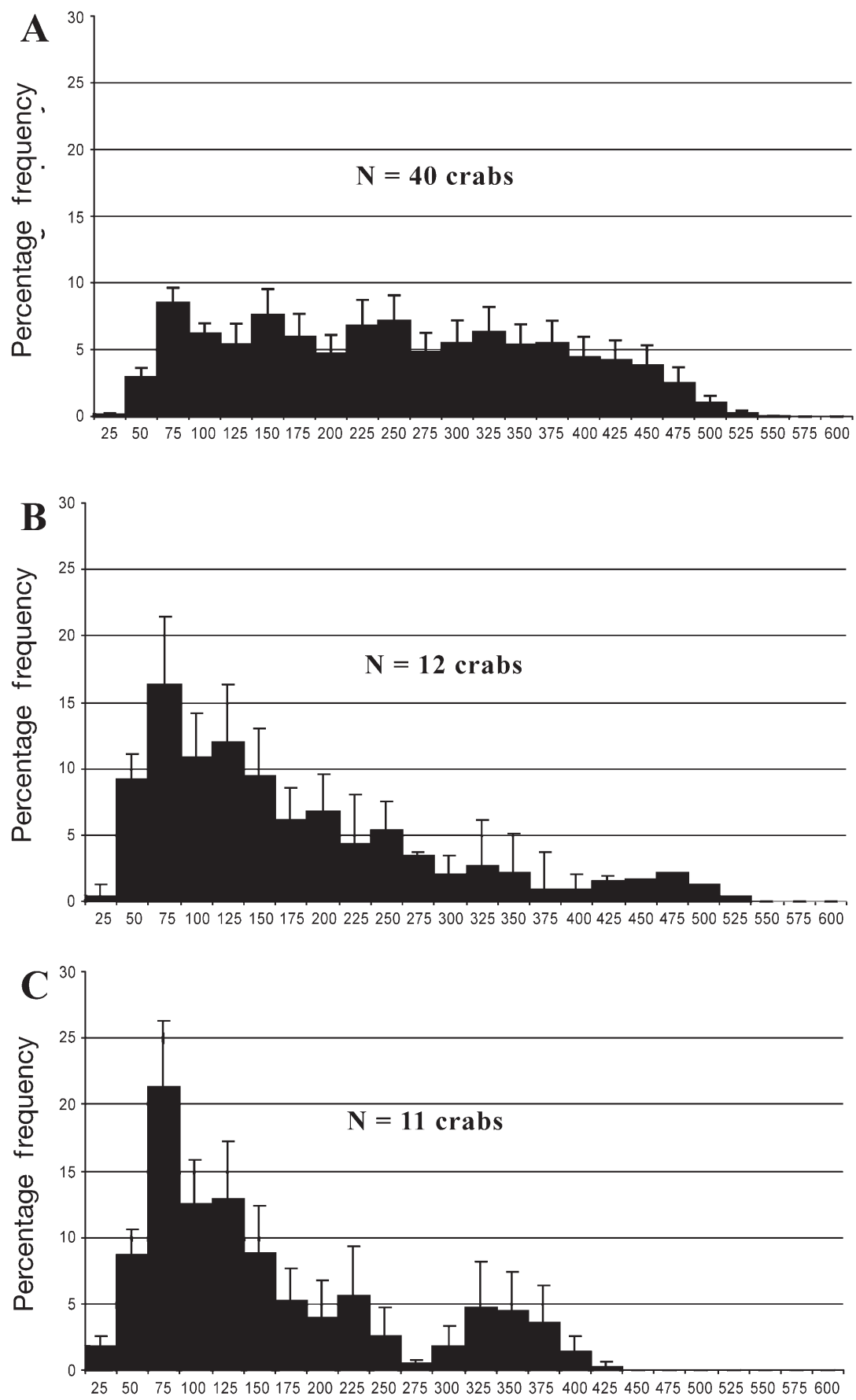

Oocyte size $(\mu \mathbf{m})$

Fig. 4. Bythograea thermydron. Mean size-frequency of oocytes of vent crabs collected during 3 cruises to vent sites in East Pacific Rise. Error bars represent 1 SE. (A) November 1997; (B) May 2000; (C) May 1999

expected frequencies of males (0.5) and females (0.5) in either November 1997 or May 2000, but did indicate a significant difference in May 1999 (Table 2).

However, when the data were grouped by sampling site (AV zone and AP zone), there was always a signif- icant difference between observed and expected frequencies (Table 2). The frequency of females was always higher in the AP zone, while the frequency of males was always greater in the AV zone. The similarity between months and the complete reversal of the percentages of males and females in the 2 sampling zones is striking.

\section{DISCUSSION}

The results of our investigation indicate that general aspects of ovarian morphology in the hydrothermal vent crab Bythograea thermydron are typical of those seen in shallow-water brachyuran crabs. Moreover, the histological characteristics of egg development in B. thermydron, from the previtellogenic stage to the mature oocyte, do not differ from those of shallowwater forms (Johnson 1980). The oocyte size-frequency distributions for $B$. thermydron individuals clearly demonstrate group-synchronous gametogenesis within the gonad, i.e. at least 2 modes of oocyte sizes are present during most of the reproductive cycle (Wallace \& Selman 1981). This suggests an iteroparous reproductive strategy, whereby the ovaries contain an immature cohort characterized by previtellogenic oocytes and oogonia and a second cohort that eventually undergoes vitellogenesis and matures. Only 1 cohort matures within the ovary at any given time. This pattern of development is typical of brachyuran crabs in general and has been reported in other species of deep-sea crabs (Haefner 1977); it shares some characteristics with the development pattern of vent shrimp (Ramirez-Llodra et al. 2000).

Our results also demonstrate a significant difference in the mean size of oocytes among groups of crabs collected in the 3 respective sampling periods. In addition, the oocyte sizefrequency data (Fig. 4) indicate a marked difference between the November sample and the 2 May samples, suggesting periodicity in the reproductive cycle of the vent crab. The 2 May samples are similar to each other, illustrating a dominance of previtellogenic 

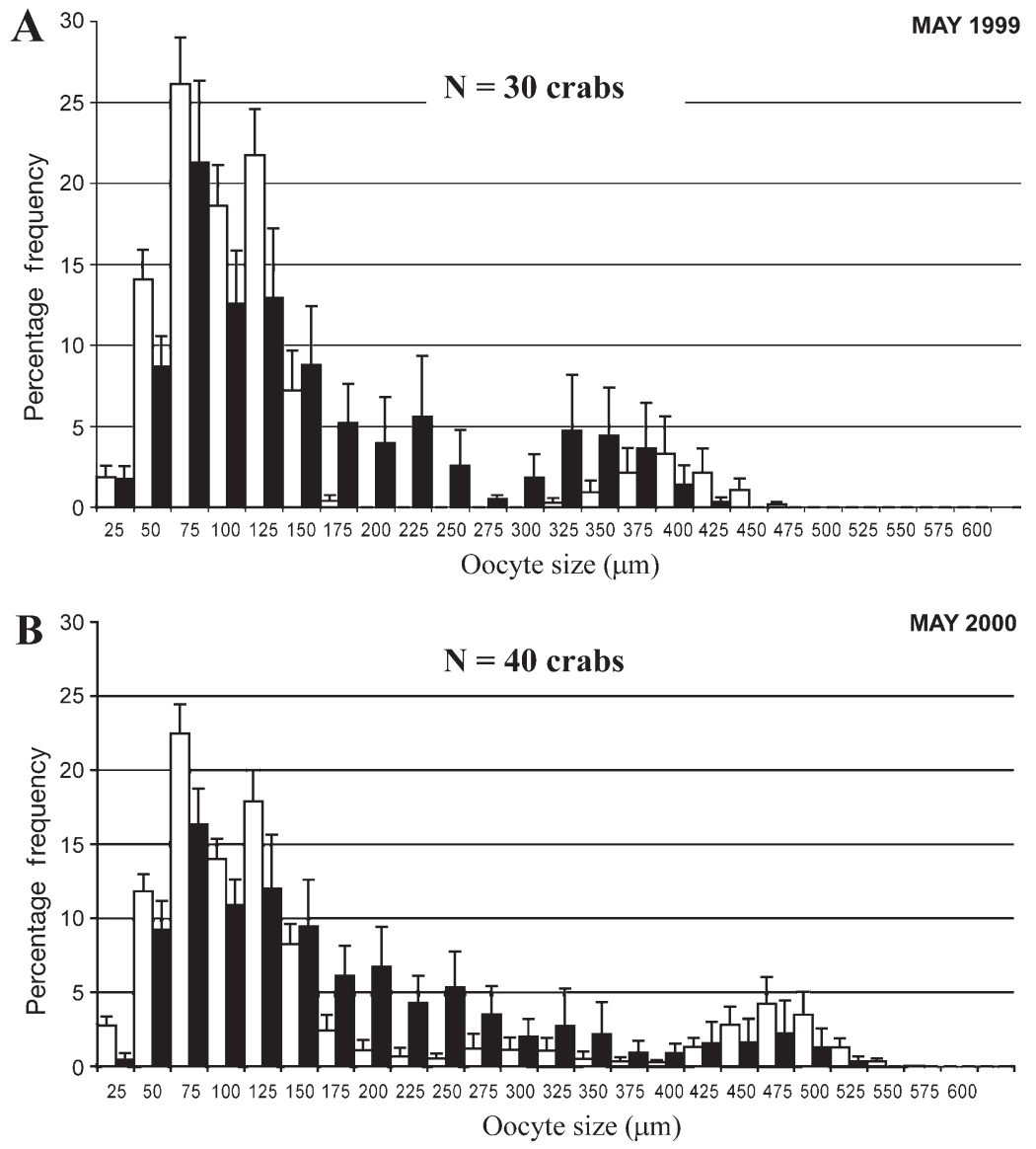

Fig. 5. Bythograea thermydron. Comparison of mean size-frequency ( $\pm \mathrm{SE}$ ) of oocytes from vent crabs collected during 2 cruises to vent fields along East Pacific Rise. Filled bars: crabs collected at vent sites (= AV zone); open bars: crabs collected immediately peripheral to vent sites (= AP zone). (A) May 1999; (B) May 2000

Table 1. Bythograea thermydron. Comparison of reproductive stage of female vent crabs at vent sites along East Pacific Rise. AV: samples collected at vent sites; AP: samples collected immediately peripheral to vent sites; pre-brooding: no external manifestation of eggs; remnants: evidence of recent hatching of eggs; gravid: brood of eggs attached to abdomen. Values are number of crabs in each category

\begin{tabular}{|lrrrrrr|}
\hline \multirow{2}{*}{ Reproductive stage } & \multicolumn{3}{c}{ May 1999 } & \multicolumn{3}{c|}{ May 2000 } \\
& Total & AV & AP & Total & AV & AP \\
& & & & & & \\
Pre-brooding & 21 & 12 & 9 & 19 & 10 & 9 \\
Light remnants & 2 & 2 & 0 & 4 & 3 & 1 \\
Heavy remnants & 12 & 0 & 12 & 19 & 1 & 18 \\
Gravid & 0 & 0 & 0 & 4 & 0 & 4 \\
Total sample & 35 & 14 & 21 & 46 & 14 & 32 \\
\hline
\end{tabular}

stages of maturity, while the May samples are indicative of the end of a spawning period, i.e. the high frequency of previtellogenic oocytes corresponds to the recent extrusion, brooding, and hatching of the cohort of mature oocytes. The lack of directed sampling at the vent periphery in November complicates interpretation of the data and has also resulted in a reduction in the number of crabs we could include in this analysis from the May samples. We do not believe this smaller sample size biases interpretation of the data. However, given that a wide variety of stages were observed in the immediate vent area in November, it is possible that gravid females could have been obtained at the vent periphery at that time. Because limited seasonal samples require cautious interpretation, we have proposed the simplest scenario. We recognize that alternative interpretations might include adjustments to duration of the cycle, specifically concerning the duration of egg brooding. Thus, we suggest a reproductive cycle in which peak egg hatching occurs in April-May, as characterized by the high percentage of females bearing evidence of recent brood release in both May samples and a preponderance of previtellogenic oocytes within the population. This type of seasonal reproductive cycle was also documented for the deep-water crab Chaceon quinquedens, despite the fact that ovigerous females were captured in all seasons (Haefner 1978). Likewise, annual reproductive cycles showing peaks of eggbearing females have also been documented for shallow-water brachyurans (Haddon and Wear 1993). Additionally, Erdman et al. (1991) suggest that while both $C$. fenneri and C. quinquedens reproduce annually at the population level, some individuals may reproduce biennially. More difficult to ascertain, however, are the reasons behind such a pattern in an environment of constant food supply and devoid of any marked seasonality.

oocytes with a second smaller group of vitellogenic oocytes present. In contrast, the November sample has a wide variety of oocyte sizes with no one size class predominating. The November data are indicative of a population comprised of individuals exhibiting various
In general, little is known about the endogenous or exogenous factors that control reproductive cycles in the deep sea (Company \& Sarda 1997). Schoener (1968) first suggested that variation in the flux of particulate food material to the deep sea might cue seasonality in 
Table 2. Bythograea thermydron. Comparison of numbers of male and female vent crabs collected during 3 cruises to hydrothermal vent sites along East Pacific Rise. Values compared by chi-square analysis. Expected proportions of males and females $=1: 1 . \mathrm{p}$ : probability of rejecting null hypothesis $(\alpha: 0.05) ; A V:$ samples collected at vent sites; AP: samples collected immediately peripheral to vent sites

\begin{tabular}{|c|c|c|c|}
\hline Sample & Males & Females & $\mathrm{p}$ \\
\hline Nov 1997 & 46 & 54 & 0.424 \\
\hline May 1999 & 67 & 35 & $<0.001$ \\
\hline May 2000 & 62 & 46 & 0.124 \\
\hline May 1999 AV & 58 & 14 & $<0.001$ \\
\hline $\mathrm{AP}$ & 9 & 21 & $<0.001$ \\
\hline \multirow{2}{*}{ May 2000} & 47 & 14 & 0.029 \\
\hline & 15 & 32 & 0.013 \\
\hline
\end{tabular}

reproductive activity. In recent years, this idea has been recast as the phytodetrital-flux hypothesis, whereby variation in the flux of surface-produced particulate material to the sea floor would serve as the cue for seasonal spawning (Gage \& Tyler 1991).

Tyler et al. (1983) observed that a number of deepsea echinoderms from the Rockall Trough in the NE Atlantic basin produced planktotrophic larvae and synchronized their time of spawning to occur simultaneously with the sinking of organic matter from the phytoplankton bloom that occurs each spring in surface waters above the Trough. In contrast, this synchronization was absent in co-occurring echinoderms whose mode of larval development is lecithotrophic. More recently, a relationship has been demonstrated between the onset of vitellogenesis and the sinking of phytodetrital matter in Leucon profundus, an abyssal cumacean, also from the Rockall Trough (Bishop \& Shalla 1994). In addition, field and laboratory experiments involving the majid crab Chionoecetes opilio have shown that larval release is linked to phytodetrital deposition (Starr et al. 1994).

It is well known that phytoplankton blooms occur seasonally (spring and summer) in the surface waters of the tropical Eastern Pacific (Longhurst 1993). Sediment analysis has shown that phytodetritus reaches the sea-floor in this area in amounts that could yield significant contributions to the annual carbon budget of the benthic community (Smith et al. 1996). However, Smith et al. reported that chlorophyll-rich detritus was only found from $5^{\circ} \mathrm{S}$ to $5^{\circ} \mathrm{N}$, with the highest concentration within 2 to $3^{\circ}$ of the equator. Sediment samples at $9^{\circ} \mathrm{N}$ revealed a brown flocculent material that contained very few diatom remains, little chlorophyll, and few zooplankton fecal pellets. Smith et al. (1996) concluded that the material had not recently arrived at the sea floor. Accordingly, it seems unlikely that phytodetrital flux, per se, plays a major role in the reproduc- tive biology of $B$. thermydron. However, present information suggests that larval development in Bythograea thermydron is planktotrophic (Van Dover 2000). Moreover, the larval stages appear to have a wide tolerance for variation in temperature and pressure and have the physiological potential to exploit a large portion of the water column over the vents (Epifanio et al. 1999). Therefore, variation in surface production may have a direct effect on the nutritional environment to which the larvae are exposed and, thus, an indirect effect on the seasonality of reproductive activity in the adults. For example, a recent study on Rimicaris exoculata from mid-Atlantic hydrothermal vents presented evidence that photosynthetically-derived $\Omega-3$ fatty acids, thought to be necessary for adult reproduction, are originally acquired during the juvenile stage in this shrimp (Allen et al. 2001).

Regardless of the uncertainty concerning proximate cues, our data clearly indicate a pattern of seasonality in the reproductive activity of Bythograea thermydron. Moreover, the female crabs appear to utilize different areas of the vent field during different phases of oocyte development. For example, there was a significant difference between the mean sizes of oocytes from the AV and AP zones during May 2000, and graphical analysis showed that the majority of previtellogenic and very mature oocytes are contributed by samples from the AP zone in both May 1999 and May 2000, while the majority of intermediate oocytes are contributed by those samples from the AV zone (Fig. 5). Moreover, the AP samples from both years were dominated by females that were either brooding eggs or showed clear evidence of having recently hatched eggs, and the proportion of females compared to males was consistently higher at the AP sites. Thus, it appears that females migrate to the vent periphery in order to undergo the processes of fertilization, extrusion, external brooding, and eventual hatching of eggs.

It is not clear why females would leave the ventorifice region in order to brood and hatch their eggs. However, the lack of brooding females in the AV zone has also been reported for 1 species of hydrothermal vent shrimp from the Mid-Atlantic Ridge (RamirezLlodra et al. 2000). Earlier work with various species of the deep-sea crab genus Geryon has also documented a migration of brooding females away from the general population of adults (Haefner 1978, Melville-Smith 1985). Thus, there may be some general advantage in this type of behavior. The simplest explanation for Bythograea thermydron is that the behavior evolved so as to maximize survival of larvae. Relatively high temperatures, combined with vent fluids rich in sulfide and heavy metals, may be toxic to larvae. Additionally, the vent periphery does not have the dense aggregations 
of biota that characterize the near-orifice region; thus, predation on newly hatched larvae would likely be minimized in the AP zone. Finally, larvae hatched in the AP zone would not be entrained in the vent plume, but rather would be dispersed in the ambient bottom currents or could migrate to higher positions in the water column extraneous to the plume (Kim \& Mullineaux 1998). The advantages of this type of dispersal are not clear, but Epifanio et al. (1999) suggest that $B$. thermydron larvae are well equipped physiologically to deal with environmental conditions ranging from the ambient deep-sea to the tropical surface waters above the vents.

\section{CONCLUSIONS}

The results of our study provide strong evidence that, at vent sites along the East Pacific Rise, Bythograea thermydron undergoes a seasonal cycle of reproductive activity, with egg hatching peaking in April-May. Typical of brachyuran crabs in general, the females undergo a synchronous pattern of oocyte development, whereby one cohort of oocytes undergoes vitellogenesis, while a second cohort is present, developing only after mature oocytes are extruded onto the pleopods. Comparison of the mean oocytesize-frequency distributions of all crabs in a given month revealed that the 2 May samples were similar to each other, exhibiting a dominance of previtellogenic oocytes in the population with a second, smaller group of vitellogenic oocytes present. In contrast, the November sample exhibited a wide variety of oocyte sizes; with no one size class predominating. Finally, the May samples from the AP zone contained a high proportion of females that showed evidence of recent egg hatching.

The data suggest an annual cycle whereby a given cohort of oocytes is in a previtellogenic state in early spring (April-May), but has begun vitellogenesis by late autumn (November) and has developed to maximum maturity by the time the eggs are extruded the following spring. While the current clutch of eggs is being brooded, a second cohort of previtellogenic oocytes begins to develop in the ovary and the cycle is repeated. Superimposed on this annual cycle is a pattern of behavior whereby females with mature gonads migrate to the vent periphery, where their eggs are fertilized, extruded, brooded, and hatched. It is not known how long females brood the eggs, but all ovigerous females collected in our May samples were brooding eggs that were ready to hatch. Likewise, it is not known when actual copulation occurs, nor is it known if this occurs at the vent orifice or at the vent periphery.
Acknowledgements. This study was supported by Grant OCE-9618007 (to S. C. Cary, A.I.D., and C.E.E.) as part of the LARVE initiative of The National Science Foundation. The authors would like to thank S. C. Cary for comments on an early version of the manuscript and for assistance with cruise planning and logistics. We thank the captain and crew of the RV 'Atlantis' and deep-sea submersible 'Alvin' for assistance in collecting specimens, as well as Lauren Mullineaux and Donal Manahan for sharing ship-time on the DISPO cruise. We also thank Geremea Fioravanti, Cathy Allen and Brandon Jones for assistance with shipboard dissections and Douglas Miller for assistance with statistical analyses. Finally, we also extend our gratitude to the students of Paul Tyler's laboratory, particularly Eva Ramirez-Llodra, for their instruction and support with the image analysis.

\section{LITERATURE CITED}

Allen CE, Copley JT, Tyler PA (2001) Lipid partitioning in the hydrothermal vent shrimp Rimicaris exoculata. PSZN I: Mar Ecol 22:241-253

Bishop JDD, Shalla SH (1994) Discrete seasonal reproduction in an abyssal peracarid crustacean. Deep-Sea Res 41: $1789-1800$

Campos-Creasey LS, Tyler PA, Gage JD, John AWG (1994) Vertical flux coupled to the diet and seasonal life history of the deep-sea echinoid Echinus affinis. Deep-Sea Res 41: $369-388$

Childress JJ, Fisher CR (1992) The biology of hydrothermal vent animals: physiology, biochemistry, and autotrophic symbioses. Oceanogr Mar Biol Annu Rev 30:337-441

Company JB, Sarda F (1997) Reproductive patterns and population characteristics in five deep-water pandalid shrimps in the Western Mediterranean along a depth gradient (150-1100 m). Mar Ecol Prog Ser 148:49-58

Epifanio CE, Perovich G, Dittel AI, Cary SC (1999) Development and behavior of megalopa larvae and juveniles of the hydrothermal vent crab Bythograea thermydron. Mar Ecol Prog Ser 185:147-154

Erdman RB, Blake NJ, Lockhart FD, Lindberg WJ, Perry HM, Waller RS (1991) Comparative reproduction of the deepsea crabs Chaceon fenneri and C. quinquedens (Brachyura: Geryonidae) from the northeast Gulf of Mexico. Invertebr Reprod Dev 19(3):175-184

Gage JD, Tyler PA (1991) Deep-sea biology: a natural history of organisms at the deep-sea floor. Cambridge University Press, New York

George RY, Menzies RJ (1967) Indication of cyclic reproductive activity in abyssal organisms. Nature 215:878

George RY, Menzies RJ (1968) Further evidence for seasonal breeding cycles in deep sea. Nature 220:80-81

Giese AC (1959) Comparative physiology: annual reproductive cycles of marine invertebrates. Annu Rev Physiol 21: $257-276$

Grassle JF (1986) The ecology of deep-sea hydrothermal vent communities. Adv Mar Biol 23:301-362

Haddon M, Wear RG (1993) Seasonal incidence of egg-bearing in the New Zealand paddle crab Ovalipes catharus (Crustacea: Brachyura), and its production of multiple egg batches. NZ J Mar Freshw Res 27:287-293

Haefner PA Jr (1977) Reproductive biology of the female deep-sea red crab, Geryon quinquedens, from the Chesapeake Bight. Fish Bull US Fish Wild L Serv 75(1):91-102

Haefner PA Jr (1978) Seasonal aspects of the biology, distribution and relative abundance of the deep-sea red crab Geryon quinquedens Smith, in the vicinity of the Norfolk 
Canyon, western North Atlantic. Proc Natl Shellfish Assoc 68:49-62

Harrison K (1988) Seasonal reproduction in deep-sea Crustacea (Isopoda: Asellota). J Nat Hist 22:175-177

Hessler RR, Kaharl VA (1995) The deep-sea hydrothermal vent community: an overview. Geophys Monogr 91:72-84

Hessler RR, Smithey WM, Keller CH (1985) Spatial and temporal variation of giant clams, tube worms and mussels at deep-sea hydrothermal vents. Bull Biol Soc Wash 6: 411-428

Johnson PT (1980) The histology of the blue crab, Callinectes sapidus. Praeger Publishers, New York

Kim SL, Mullineaux LS (1998) Distribution and near-bottom transport of larvae and other plankton at hydrothermal vents. Deep-Sea Res Part B 45:423-440

Longhurst A (1993) Seasonal cooling and blooming in tropical oceans. Deep-Sea Res 40:2145-2165

Melville-Smith R (1985) Density distribution by depth of Geryon maritae on the northern crab grounds of south west Africa/Namibia determined by photography in 1983, with notes on the portunid crab Bathynectes piperitus. S Afr J Mar Sci 3:55-62

Mickel TJ, Childress JJ (1982a) Effects of temperature on the EKG and heart rate of the hydrothermal vent crab, Bythograea thermydron (Brachyura). Bull Biol Soc Washington 162:70-82

Mickel TJ, Childress JJ (1982b) Effects of temperature, pressure and oxygen concentration on the oxygen consumption rate of the hydrothermal vent crab, Bythograea thermydron (Brachyura). Physiol Zool 55:199-207

Orton JH (1920) Sea temperature, breeding and distribution in marine animals. J Mar Biol Assoc UK 12:339-366

Ramirez-Llodra ER, Tyler PA, Copley JTP (2000) Reproductive biology of three caridean shrimp, Rimicaris exoculata, Chorocaris chacei and Mirocaris fortunate (Caridea: Decapoda), from hydrothermal vents. J Mar Biol Assoc UK 80(3597):1-12

Editorial responsibility: Otto Kinne (Editor), Oldendorf/Luhe, Germany
Rokop FJ (1974) Reproductive patterns in the deep-sea benthos. Science 186:743-745

Rokop FJ (1977) Patterns of reproduction in the deep-sea benthic crustaceans: a re-evaluation. Deep-Sea Res 24: 683-691

Schoener A (1968) Evidence for reproductive periodicity in the deep sea. Ecology 49(1):81-87

Smith CR, Hoover DJ, Doan SE, Pope RH, Demaster DJ, Dobbs FC, Altabet MA (1996) Phytodetritus at the abyssal seafloor across $10^{\circ}$ of latitude in the central equatorial Pacific. Deep-Sea Res Part B 43(4-6):1309-1338

Starr M, Therriault JC, Conan GY, Comeau M, Robichaud G (1994) Larval release in a sub-euphotic zone invertebrate triggered by sinking phytoplankton particles. J Plankton Res 16:1137-1147

Tyler PA (1986) Studies of a benthic time series: reproductive biology of benthic invertebrates in the Rockall Trough. Proc R Soc Edinb 88:175-190

Tyler PA (1988) Seasonality in the deep sea. Oceanogr Mar Biol Annu Rev 26:227-258

Tyler PA, Grant A, Pain SL, Gage JD (1983) Is annual reproduction in deep-sea echinoderms a response to variability in their environment? Nature Sect B (Biol) 300:747-750

Van Dover (2000) The ecology of deep-sea hydrothermal vents. Princeton University Press, Princeton, NJ

Van Dover CL, Franks PJS, Ballard RD (1987) Prediction of hydrothermal vent locations from distributions of brachyuran crabs. Limnol Oceanogr 32:1006-1010

Vetter RD, Wells ME, Kurtsman AL, Somero GN (1987) Sulfide detoxification by the hydrothermal vent crab Bythograea thermydron and other decapod crustaceans. J Physiol Zool 60:121-137

Wallace R, Selman K (1981) Cellular and dynamic aspects of oocyte growth in teleosts. Am Zool 21:325-343

Williams A (1980) A new crab family from the vicinity of submarine thermal vents of the Galapagos rift (Crustacea: Decapoda: Brachyura). Proc Biol Soc Wash 93(2):443-472

Submitted: July 20, 2002; Accepted: December 17, 2002 Proofs received from author(s): March 18, 2003 